\title{
SYNTHESIS AND ANTICONVULSANT ACTIVITY (CHEMO SHOCK) OF N-1(SUBSTITUTED-N- 4[(4-OXO-3-PHENYL-3, 4-DIHYDRO-QUINAZOLINE-2-YLMETHYL) SEMICARBAZONES
}

\author{
MEENA K YADAV ${ }^{1 *}$, LAXMI TRIPATHI ${ }^{2}$, DIPTENDU GOSWAMI ${ }^{3}$ \\ ${ }^{1}$ Department of Pharmaceutical Chemistry , Mahatma Gandhi Institute of Pharmacy, Lucknow, Uttar Pradesh, India. ${ }^{2}$ Moradabad \\ Educational Trust, Group of Institutions, Faculty of Pharmacy, Moradabad, Uttar Pradesh, India. ${ }^{3}$ Faculty of Pharmacy, Naraina Vidya Peeth \\ Group of Institutions, Kanpur, Uttar Pradesh, India. Email: meenayadav82@gmail.com
}

Received: 31 December 2016, Revised and Accepted: 09 January 2017

\section{ABSTRACT}

Objective: This work is designed at finding new structure leads with potential anticonvulsant activities of $4(3 \mathrm{H})$-quinazolinone pharmacophore scaffold.

Methods: A new series of 4(3H)-quinazolinone pharmacophore was designed with substituted moieties possesses different electronic environment in the hope of developing potent and safe new effective compounds. In such fashion, in this paper, we report the synthesis and anticonvulsant activity (Chemo shock) of N-1(substituted-N-4[(4-oxo-3-phenyl-3, 4-dihydro-quinazoline-2-ylmethyl) semicarbazones 3A-d (1-7), 3B-d (1-7), 3C-d (1-7), their chemical structure were characterized using IR, ${ }^{1} \mathrm{H}-\mathrm{H}$ NMR, and elemental analysis techniques. Their anticonvulsant activity was evaluated using chemicals strychnine, thiosemicarbazide and 4-aminopyridine induced seizure models at a dose of 30,100, $300 \mathrm{mg} / \mathrm{kg}$ unto 2 hrs tests in mice. The rotarod assay was performed in mice to evaluate the neurotoxicity of the compounds.

Results: Compounds 3C (d-4), 3B (d-4), and 3A (d-4) were observed to be most feasible to act against glutamate receptor for anticonvulsant activity.

Conclusions: The results obtained revealed that numbers of novel quinazolinone semicarbazone derivatives are effective in chemical to induce (chemo shock) model and showing good anticonvulsant activity.

Keywords: Quinazolinone, Semicarbazones, Strychnine, Thiosemicarbazide, 4-aminopyridine, Anticonvulsant activity, Chemo shock.

(c) 2017 The Authors. Published by Innovare Academic Sciences Pvt Ltd. This is an open access article under the CC BY license (http://creativecommons. org/licenses/by/4. 0/) DOI: http://dx.doi.org/10.22159/ajpcr.2017.v10i4.16876

\section{INTRODUCTION}

Epilepsy is regarded as a multifactor and symptomatologically highly diversified neurological disorder result from long-lasting plastic changes in the brain affecting neurotransmitter release, the properties of receptors and channels, synaptic reorganization and astrocyte activity. It inflicts more than 60 million people worldwide according to epidemiological studies [1,2]. Different chemical classes such as hydantoins, barbiturates, benzodiazepines, gamma-amino butyric acid (GABA) analogs, dibenzazepines, and carbamates are known to be part of anti-epileptic scaffolds [3-8]. Several of these drugs are known to act through modulating the GABAergic and glutamate/aspartate systems. Glutamate, the major fast excitatory neurotransmitter in the brain, play a significant role in brain development, affecting neuronal migration, neuronal differentiation, axon genesis, and neuronal survival $[9,10]$. Glutamate activates a number of pharmacologically distinct subtypes $[11,12]$ and plays an essential role in long-term potentiation [13] brought on the identification that most excitatory neurotransmission in the central nervous system (CNS) is mediated by glutamate receptors. They are important mediators of a wide range of neuronal functions from primary sensory perception to cognition [14-17]. Glutamate receptors also play a role in a number of neurodegenerative diseases and epilepsy [18]. L-glutamate can be synthesized in nerve terminals from a-ketoglutarate (formed from gluconeogenesis and the tricarboxylic acid cycle) by the enzyme glutamate dehydrogenase, and from glutamine by the glutaminase enzyme $[19,20]$. The release of glutamate gets elevated in epilepsy. The majority of antiepileptic drugs reduce the release of excitatory glutamate by blocking sodium or calcium channels, activation of GABA, inhibition of glutamate receptor, and activation of peroxisome proliferator-activated receptor alpha. Epileptic seizures occur when the excitability in certain brain circuits exceeds the restraints imposed by inhibitory mechanisms [21]. Ionotropic glutamate receptors of the AMPA and NMDA are the primary mediators of excitation in the CNS [22] and are critical to seizure generation and spread [23]. Less is known about the role of kainate receptors (KARs). KARs are also ionotropic glutamate receptors which share $40 \%$ homology with AMPA receptors and 20\% homology with NMDA receptors [24] KARs are responsible for a portion of glutamate-mediated excitation like AMPA and NMDA receptors at some synapses, inducing those in limbic regions relevant to epilepsy [25]. Axonal kainate can affect axonal excitability leading to ectopic action potentials [26]. Agonist, kainic acid, is a powerful convulsant, kainate antagonists would be expected to have antiseizure effects [27]. Literature evidence suggests that KARs are widely distributed in the CNS; represent a major target through which the convulsant kainate induces seizures and status epilepticus [28]. Various studies in brain regions have demonstrated that KARs contribute to postsynaptic excitation of principal neurons [29-32] and interneurons $[33,34]$ and also act presynaptically to modulate GABA [35] and glutamate [36] release. Some authors reported that seizure protection can be achieved through inhibition of KARs [37], whereas others have proposed that activation of these receptors is a promising antiepileptic strategy [38]. A selective, noncompetitive allosteric AMPA-receptor antagonist, perampanel, was approved for adjunctive epilepsy treatment $[39,40]$ and topiramate was approved to act at AMPA/KARs at high concentrations [41]. Glutamate receptor inhibitors (GRIs) are structurally diverse group of compounds binds to the glutamate receptor and interacts with a specific allosteric non-substrate binding pocket site. GRIs non-competitively inhibits glutamate receptor, blocks its mechanism and makes it unable to bind glutamate. $4(3 \mathrm{H})$-quinazolinones are one of the most frequently encountered heterocycles in medicinal chemistry reported having diverse pharmacological activities. A literature survey disclosed 
that the presence of a substituted aromatic ring at position 3 is the necessary requirement for the anticonvulsant activities of compounds such as methaqualone, etaqualone, mecloqualone, mebroqualone, and afloqualone. Methaqualone was an important compound in the field of synthetic anticonvulsant, possessed quinazoline core which was responsible for its activity [42]. Literature survey revealed that the semicarbazones have documented consistent advances in the design of novel anticonvulsant agents $[43,44]$ and the structure-activity relations (SAR) from accumulated semicarbazone anti-epileptics indicate that compounds providing handle for (a) aryl binding site with a hydrophobic group, (b) hydrogen bonding domain, (c) lone pair of electrons, and (d) moieties for hydrophobic interaction are favorable for the activity. The aim of this study, therefore to synthesize new series of quinazolinone semicarbazone derivatives with the purpose of considering their possible anticonvulsant activity by chemo shock method.

\section{METHODS}

\section{Experimental}

Melting points were determined in open capillary tubes and are uncorrected. The homogeneity of the compounds was monitored by thin layer chromatography (TLC) using silica gel G as a stationary phase and visualized by iodine vapors. Solvent system was chloroform:methanol (9:1). Microanalysis of the compounds was done on Perkin-Elmer model 240 analyzer, and the values found within $\pm 0.4 \%$ of the theoretical values. ${ }^{1} \mathrm{H}-\mathrm{H}$ NMR spectra were recorded on DPX$300 \mathrm{H}$ NMR spectrometer and BRUKER-400 Ultra shield ${ }^{\mathrm{TM}}$ spectrometer. Chemical shifts $(\delta)$ are expressed in ppm relative to tetramethylsilane. The IR spectra were recorded in KBr pellets on BIO-RAD FTS, IR spectrophotometer. All the chemicals and solvents used were procured from Merck (India), S. D. Fine Chemicals (India) \& Rankem (India).

General procedure for synthesis of compounds 3A-d (1-7), 3B-d (1-7), 3C-d (1-7) derivatives

Compounds 3A-d (1-7), 3B-d (1-7), 3C-d (1-7), were synthesized as describe in Schemes 1 and 2. The N-chloroacetyl anthranilic acid analog 2 was obtained by reacting anthranilic acid (1.45 mmol) 1 with chloroacetyl chloride $(21.9 \mathrm{mmol})$ in the presence of sodium bicarbonate in tetrahydrofuran at $0-5^{\circ} \mathrm{C}$. Analogue $2(4.59 \mathrm{mmol})$ was further refluxed with substituted anilines $(5.51 \mathrm{mmol})$ in the presence of phosphorous oxychloride in tetrahydrofuran for $1 \mathrm{~h}$ to yield 2-chloromethyl-3-sustituted aryl-3H-quinazoline-4-one 3A, 3B, 3C derivatives Scheme 1. Compounds 3A, 3B, 3C were converted to corresponding amines derivatives $3 \mathrm{~A}-\mathrm{a}, 3 \mathrm{~B}-\mathrm{a}, 3 \mathrm{C}-\mathrm{a}$ by reaction with ammonia which was further reacted with sodium cyanate in the presence of catalytic amount of glacial acetic acid to produce urea derivatives 3A-b, 3B-b, 3C-b as per previously known urea preparation method [45-47]. Different substituted semicarbazides 3A-c, 3B-c, 3C-c were obtained by condensation of these urea derivatives with hydrazine hydrate in ethanol under basic condition. The semicarbazone 3A-d (1-7), 3B-d (1-7), 3C-d (1-7), derivatives were prepared by reaction of the appropriate aryl/cycloalkyl aldehyde or ketone listed in Table 1 with the corresponding semicarbazide in glacial acetic acid Scheme 2 . Final compounds were washed with brine solution and treated with $\mathrm{Na}_{2} \mathrm{SO}_{4}$. TLC was performed throughout the reactions to optimize the reactions for purity and completion. The physical data for the newly synthesized compounds are presented in Table 2 . The formation of the title compounds was confirmed by its IR and ${ }^{1} \mathrm{H}-\mathrm{H}$ NMR spectral studies.

Characterization of N-1(substituted-N-4[(4-oxo-3-phenyl-3, 4-dihydroquinazoline-2-ylmethyl) semicarbazones derivatives are as follows:

2(chloromethyl)3phenylquinazolin4(3H)one(3A)IR $\quad\left(\mathrm{KBr}, \quad \mathrm{cm}^{1}\right)$ $3382(\mathrm{ArH}), 1680(\mathrm{C}=\mathrm{C}), 1580(\mathrm{C}=\mathrm{N}), 1550(\mathrm{C}-\mathrm{C}), 1700(\mathrm{C}=0)$, $1260\left(\mathrm{CH}_{2} \mathrm{Cl}\right),{ }^{1} \mathrm{H}$ NMR $\left(300 \mathrm{MHz}, \mathrm{CDCl}_{3}, \mathrm{ppm}, \delta\right): 6.75(\mathrm{~m}, 4 \mathrm{H}, \mathrm{ArH})$, $7.20(\mathrm{~m}, 5 \mathrm{H}, \mathrm{ArH}), 2.70\left(\mathrm{~s}, 2 \mathrm{H}, \mathrm{CH}_{2}\right)$, anal. Calcd for; $\mathrm{C}_{15} \mathrm{H}_{11} \mathrm{ClN}_{2} \mathrm{O}(270.71)$ (\%): Found $=\mathrm{C}(66.55) \mathrm{H}(4.10) \mathrm{N}(10.35)$ calculated $=\mathrm{C}(66.61) \mathrm{H}(4.31)$ $\mathrm{N}(10.38)$

2-(chloromethyl)-3-(4-chlorophenyl) quinazolin-4(3H)-one (3B) IR (KBr, cm $\left.{ }^{-1}\right) 3387(\mathrm{Ar}-\mathrm{H}), 1688(\mathrm{C}=\mathrm{C}), 1600(\mathrm{C}=\mathrm{N}), 1555$ (C-C), $1705(\mathrm{C}=0), 1263\left(\mathrm{CH}_{2} \mathrm{Cl}\right),{ }^{1} \mathrm{H}$ NMR $(300 \mathrm{MHz}, \mathrm{CDCl} 3, \mathrm{ppm}, \delta): 6.71$ $(\mathrm{m}, 4 \mathrm{H}, \mathrm{ArH}), 7.23(\mathrm{~m}, 5 \mathrm{H}, \mathrm{ArH}), 2.71\left(\mathrm{~s}, 2 \mathrm{H}, \mathrm{CH}_{2}\right)$, anal. Calcd for; $\mathrm{C}_{15} \mathrm{H}_{10} \mathrm{C}_{12} \mathrm{~N}_{2} \mathrm{O}$ (305.16) (\%): Found = C (59.04) H (3.30) N (9.18) calculated $=\mathrm{C}(59.34) \mathrm{H}(3.42) \mathrm{N}$ (9.39).

2-(chloromethyl)-3-(4-nitrophenyl) quinazolin-4(3H)-one (3C) IR (KBr, cm$\left.{ }^{-1}\right) 3384(\mathrm{Ar}-\mathrm{H}), 1685$ (C=C), $1590(\mathrm{C}=\mathrm{N}), 1554$ (C-C), $1710(\mathrm{C}=0), 1265\left(\mathrm{CH}_{2} \mathrm{Cl}\right),{ }^{1} \mathrm{H}$ NMR $\left(300 \mathrm{MHz}, \mathrm{CDCl}_{3}, \mathrm{ppm}, \delta\right): 6.70$ (m, 4H, Ar- $\mathrm{H}), 7.25(\mathrm{~m}, 5 \mathrm{H}, \mathrm{ArH}), 2.73\left(\mathrm{~s}, 2 \mathrm{H}, \mathrm{CH}_{2}\right)$, anal. Calcd for; $\mathrm{C}_{15} \mathrm{H}_{10} \mathrm{ClN}_{3} \mathrm{O}_{3}$ (315.71) (\%): Found $=\mathrm{C}(57.06) \mathrm{H}$ (3.19) $\mathrm{N}$ (13.31) calculated $=\mathrm{C}(57.16) \mathrm{H}(3.10) \mathrm{N}(13.50)$.

(2E)-2-(4-chlorobenzylidene) - N- [ (4-oxo-3 -phenyl-3,4dihydroquinazolin-2-yl)methyl]hydrazinecarboxamide 3A(d-1) IR $\left(\mathrm{KBr}, \mathrm{cm}^{-1}\right) 3382(\mathrm{Ar}-\mathrm{H}), 1687(\mathrm{C}=\mathrm{C}), 1610(\mathrm{C}=\mathrm{N}), 1551$ (C-C), 1722 $(\mathrm{C}=0), 3360(\mathrm{~N}-\mathrm{H}), 1090(\mathrm{Ar}-\mathrm{Cl}), 1665(\mathrm{C}=\mathrm{N}$ str of $\mathrm{NHN}=\mathrm{C}) ;{ }^{1} \mathrm{H}$ NMR (300 MHz, $\left.\mathrm{CDCl}_{3}, \mathrm{ppm}, \delta\right): 6.72(\mathrm{~m}, 4 \mathrm{H}, \mathrm{Ar}-\mathrm{H}), 7.22(\mathrm{~m}, 5 \mathrm{H}, \mathrm{ArH})$, $2.69\left(\mathrm{~s}, 2 \mathrm{H}, \mathrm{CH}_{2}\right) 4.49(\mathrm{~s}, 1 \mathrm{H}, \mathrm{NH}), 11.32(\mathrm{~s}, 1 \mathrm{H}, \mathrm{CONH})$, anal. Calcd for; $\mathrm{C}_{23} \mathrm{H}_{18} \mathrm{ClN}_{5} \mathrm{O}_{2}$ (431.11) (\%): Found = C (63.96) H (4.20) N (16.22) calculated $=\mathrm{C}(63.94) \mathrm{H}(4.24) \mathrm{N}(16.20)$.

$\mathrm{N}$-1(acetophenyl)-N-4 [4-oxo-3-phenyl-3,4-dihydro-quinaline-2ylmethyl)semicarbazone 3A(d-2) IR $\left(\mathrm{KBr}, \mathrm{cm}^{-1}\right) 3380(\mathrm{Ar}-\mathrm{H}), 1689$ $(\mathrm{C}=\mathrm{C}), 1610(\mathrm{C}=\mathrm{N}), 1559$ (C-C), $1711(\mathrm{C}=0), 3359(\mathrm{~N}-\mathrm{H}), 1669$ ( $\mathrm{C}=\mathrm{N}$ str of NHN=C); ${ }^{1} \mathrm{H}$ NMR (300 MHz, $\left.\mathrm{CDCl}_{3}, \mathrm{ppm}, \delta\right): 6.80(\mathrm{~m}, 4 \mathrm{H}, \mathrm{Ar}-\mathrm{H}), 7.51$ (m, 5H, ArH), $2.68\left(\mathrm{~s}, 2 \mathrm{H}, \mathrm{CH}_{2}\right) 4.40(\mathrm{~s}, 1 \mathrm{H}, \mathrm{NH}), 11.36(\mathrm{~s}, 1 \mathrm{H}, \mathrm{CONH})$, anal. Calcd for; $\mathrm{C}_{24} \mathrm{H}_{21} \mathrm{~N}_{5} \mathrm{O}_{2}$ (411.16) (\%): Found $=\mathrm{C}(70.06) \mathrm{H}(5.14) \mathrm{N}$ (17.02) calculated $=\mathrm{C}(70.16) \mathrm{H}(5.24) \mathrm{N}$ (17.22).

$\mathrm{N}-1$ (p-nitro-acetophenyl)-N-4[4-oxo-3-phenyl-3,4-dihydro-quinaline2ylmethyl)semicarbazone3A(d-3) IR (KBr, cm$\left.{ }^{-1}\right) 3384(\mathrm{Ar}-\mathrm{H}), 1690$ $(\mathrm{C}=\mathrm{C}), 1620(\mathrm{C}=\mathrm{N}), 1549(\mathrm{C}-\mathrm{C}), 1712(\mathrm{C}=0), 3351(\mathrm{~N}-\mathrm{H}), 1480(\mathrm{~N}-\mathrm{O})$, $1670(\mathrm{C}=\mathrm{N}$ str of $\mathrm{NHN}=\mathrm{C}) ;{ }^{1} \mathrm{H}$ NMR $\left(300 \mathrm{MHz}, \mathrm{CDCl}_{3}, \mathrm{ppm}, \delta\right): 6.69$

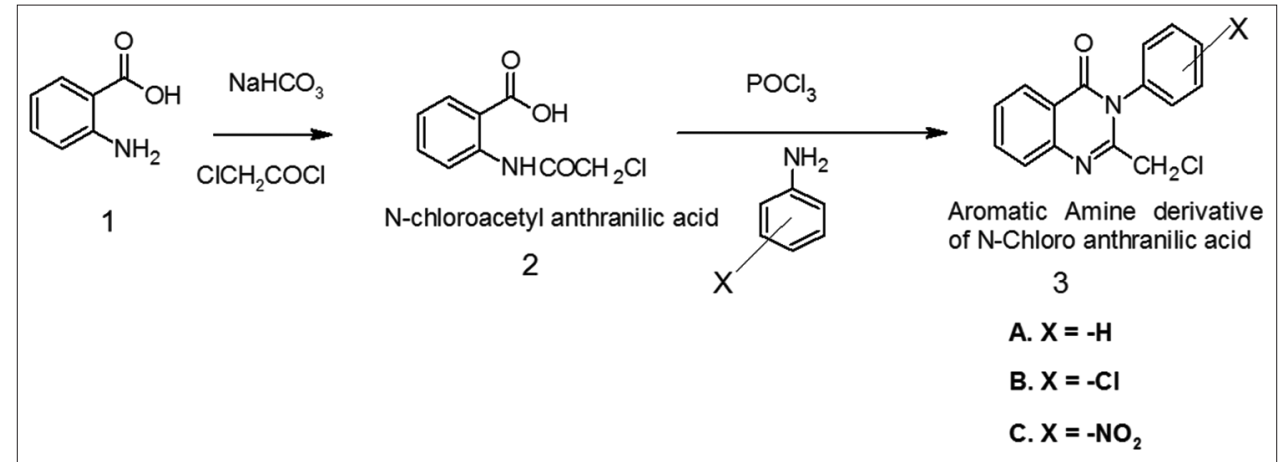

Scheme 1: Preparation procedure of different aromatic amine derivatives of N-chloro anthranilic acid 


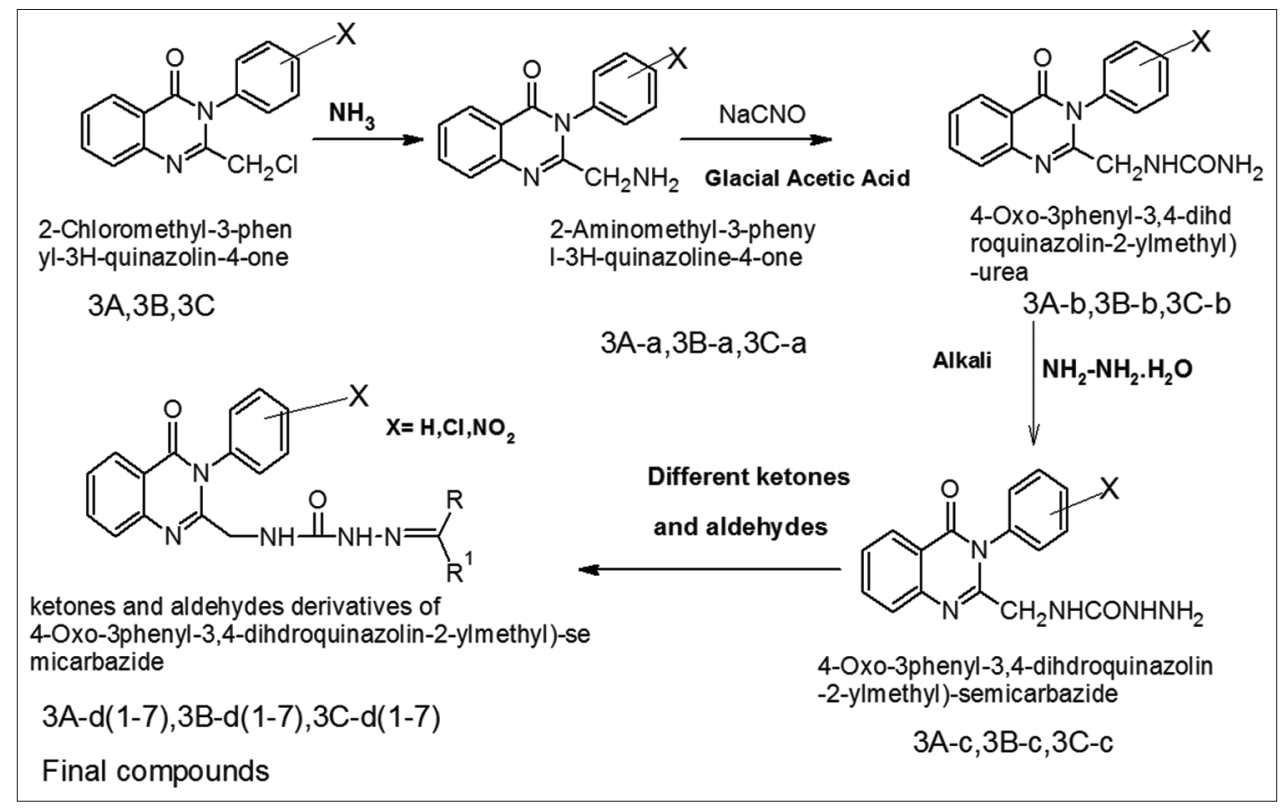

Scheme 2: Preparation procedure of quinazolinone semicarbazone derivatives

(m, 4H, Ar-H), 7.57 (m, 5H, ArH), $2.64\left(\mathrm{~s}, 2 \mathrm{H}, \mathrm{CH}_{2}\right) 4.39(\mathrm{~s}, 1 \mathrm{H}, \mathrm{NH})$, 11.37 (s, $1 \mathrm{H}, \mathrm{CONH}$ ), anal. Calcd for; $\mathrm{C}_{24} \mathrm{H}_{20} \mathrm{~N}_{6} \mathrm{O}_{4} 456.15$ ) (\%): Found = C (63.15) H (4.42) N (18.41) calculated $=\mathrm{C}(63.34) \mathrm{H}(4.56) \mathrm{N}$ (18.31).

$\mathrm{N}$-1(menthone)-N-4[(4-oxo-3-phenyl-3,4-dihydro-quinazoline-2ylmethyl)semicarbazone 3A(d-4) IR (KBr, cm $\left.{ }^{-1}\right) 3383(\mathrm{Ar}-\mathrm{H}), 1691$ $(\mathrm{C}=\mathrm{C}), 1614(\mathrm{C}=\mathrm{N}), 1550(\mathrm{C}-\mathrm{C}), 1710(\mathrm{C}=0), 3350(\mathrm{~N}-\mathrm{H}), 1672(\mathrm{C}=\mathrm{N}$ str of NHN=C); ${ }^{1} \mathrm{H}$ NMR (300 MHz, CDCl3, ppm, $\left.\delta\right): 6.71(\mathrm{~m}, 4 \mathrm{H}, \mathrm{Ar}-\mathrm{H})$, $7.53(\mathrm{~m}, 5 \mathrm{H}, \mathrm{ArH}), 2.90\left(\mathrm{~s}, 2 \mathrm{H}, \mathrm{CH}_{2}\right) 4.63(\mathrm{~s}, 1 \mathrm{H}, \mathrm{NH}), 11.39$ (s, $1 \mathrm{H}$, $\mathrm{CONH}), 1.33\left(\mathrm{~s}, 3 \mathrm{H}, \mathrm{CH}_{3}\right), 1.08\left(\mathrm{~s}, 3 \mathrm{H}, \mathrm{CH}_{3}\right), 1.23\left(\mathrm{~s}, 3 \mathrm{H}, \mathrm{CH}_{3}\right)$; anal. Calcd for; $\mathrm{C}_{26} \mathrm{H}_{31} \mathrm{~N}_{5} \mathrm{O}_{2}$ (447.16) (\%): Found = C (70.09) H (7.01) N (15.72) calculated $=\mathrm{C}$ (70.11) H (7.12) N (15.68).

$\mathrm{N}-1$ (camphor)-N-4 [(4-Oxo-3phenyl-3,4-dihdroquinazolin-2-ylmethyl)semicarbazone 3A(d-5) IR (KBr, cm-1) $3381(\mathrm{Ar}-\mathrm{H}), 1690(\mathrm{C}=\mathrm{C}), 1619$ $(\mathrm{C}=\mathrm{N}), 1560(\mathrm{C}-\mathrm{C}), 1720(\mathrm{C}=0), 3358(\mathrm{~N}-\mathrm{H}), 1678(\mathrm{C}=\mathrm{N}$ str of $\mathrm{NHN}=\mathrm{C})$; ${ }^{1} \mathrm{H}$ NMR $\left(300 \mathrm{MHz}, \mathrm{CDCl}_{3}, \mathrm{ppm}, \delta\right): 6.78(\mathrm{~m}, 4 \mathrm{H}, \mathrm{Ar}-\mathrm{H}), 7.63(\mathrm{~m}, 5 \mathrm{H}, \mathrm{ArH})$, $2.85\left(\mathrm{~s}, 2 \mathrm{H}, \mathrm{CH}_{2}\right) 4.66(\mathrm{~s}, 1 \mathrm{H}, \mathrm{NH}), 11.49$ (s, 1H, $\left.\mathrm{CONH}\right), 1.39$ (s, 3H, $\left.\mathrm{CH}_{3}\right)$; anal. Calcd for; $\mathrm{C}_{26} \mathrm{H}_{29} \mathrm{~N}_{5} \mathrm{O}_{2}$ 298.16) (\%): Found $=\mathrm{C}(69.32) \mathrm{H}(4.92) \mathrm{N}$ (18.66) calculated $=\mathrm{C}(69.42) \mathrm{H}(4.88) \mathrm{N}(18.72)$.

$\mathrm{N}$-1(furfuraldehyde)-N-4[(4-0xo-3 phenyl-3,4-dihdroquinazolin-2ylmethyl)-semicarbazone 3A(d-6) IR $\left(\mathrm{KBr}, \mathrm{cm}^{-1}\right) 3380(\mathrm{Ar}-\mathrm{H}), 1655$ $(\mathrm{C}=\mathrm{C}), 1620(\mathrm{C}=\mathrm{N}), 1561(\mathrm{C}-\mathrm{C}), 1722(\mathrm{C}=0), 3359(\mathrm{~N}-\mathrm{H}), 1668(\mathrm{C}=\mathrm{N}$ str of NHN=C), 1155 (C-O), $1220(\mathrm{C}-\mathrm{O}-\mathrm{C}) ;{ }^{1} \mathrm{H}$ NMR $\left(300 \mathrm{MHz}, \mathrm{CDCl}_{3}\right.$, ppm, $\delta): 7.78(\mathrm{~m}, 4 \mathrm{H}, \mathrm{Ar}-\mathrm{H}), 7.61(\mathrm{~m}, 5 \mathrm{H}, \mathrm{ArH}), 2.75\left(\mathrm{~s}, 2 \mathrm{H}, \mathrm{CH}_{2}\right) 4.50$ (s, 1H, NH), $11.55(\mathrm{~s}, 1 \mathrm{H}, \mathrm{CONH}), 6.71(\mathrm{~m}, 3 \mathrm{H}, \mathrm{ArH}) 5.48(\mathrm{~s}, 1 \mathrm{H}, \mathrm{CH})$; anal. Calcd for; $\mathrm{C}_{21} \mathrm{H}_{17} \mathrm{~N}_{5} \mathrm{O}_{3}$ (387.13) (\%): Found $=\mathrm{C}(65.11) \mathrm{H}(4.42) \mathrm{N}$ (18.08) calculated $=\mathrm{C}(65.19) \mathrm{H}(4.46) \mathrm{N}(18.28)$.

N-1(benzophenyl)-N-4[(4-0xo-3 phenyl-3,4-dihdroquinazolin-2ylmethyl)-semicarbazone $3 \mathrm{~A}(\mathrm{~d}-7)$ IR $\left(\mathrm{KBr}, \mathrm{cm}^{-1}\right) 3370(\mathrm{Ar}-\mathrm{H}), 1650$ $(\mathrm{C}=\mathrm{C}), 1600(\mathrm{C}=\mathrm{N}), 1551(\mathrm{C}-\mathrm{C}), 1702(\mathrm{C}=0), 3351(\mathrm{~N}-\mathrm{H}), 1668$ (C=N str of NHN=C), ${ }^{1} \mathrm{H}$ NMR $(300 \mathrm{MHz}, \mathrm{CDCl} 3, \mathrm{ppm}, \delta): 7.81(\mathrm{~m}, 4 \mathrm{H}, \mathrm{Ar}-\mathrm{H}), 7.41$ (m, 5H, ArH), $2.70\left(\mathrm{~s}, 2 \mathrm{H}, \mathrm{CH}_{2}\right) 3.40(\mathrm{~s}, 1 \mathrm{H}, \mathrm{NH}), 11.45(\mathrm{~s}, 1 \mathrm{H}, \mathrm{CONH})$, $7.95(\mathrm{~m}, 5 \mathrm{H}, \mathrm{ArH}) 6.48(\mathrm{~m}, 5 \mathrm{H}, \mathrm{ArH})$; anal. Calcd for; $\mathrm{C}_{29} \mathrm{H}_{23} \mathrm{~N}_{5} \mathrm{O}_{2}$ (473.18) (\%): Found $=\mathrm{C}(73.56) \mathrm{H}(4.90) \mathrm{N}(14.79)$ calculated $=\mathrm{C}(73.62)$ $\mathrm{H}(4.97) \mathrm{N}(14.68)$.

$\mathrm{N}$-\{[3-(4-chlorophenyl)-4-oxo-3,4-dihydroquinazolin-2-yl]methyl\}semicarbazone 3B(d-1) IR (KBr, cm$\left.{ }^{-1}\right) 3381(\mathrm{Ar}-\mathrm{H}), 1688$ (C=C), 1622 $(\mathrm{C}=\mathrm{N}), 1553(\mathrm{C}-\mathrm{C}), 1723(\mathrm{C}=\mathrm{O}), 3363(\mathrm{~N}-\mathrm{H}), 1092(\mathrm{Ar}-\mathrm{Cl}), 1664(\mathrm{C}=\mathrm{N}$ str of NHN=C); ${ }^{1} \mathrm{H}$ NMR (300 MHz, $\left.\mathrm{CDCl}_{3}, \mathrm{ppm}, \delta\right): 6.70(\mathrm{~m}, 4 \mathrm{H}, \mathrm{Ar}-\mathrm{H}), 7.20$ (m, 5H, ArH), 2.70 (s, 2H, CH2) 4.50 (s, 1H, NH), 11.33 (s, 1H, CONH), anal. Calcd for; $\mathrm{C}_{23} \mathrm{H}_{17} \mathrm{C}_{12} \mathrm{~N}_{5} \mathrm{O}_{2}$ (465.07) (\%): Found = C (59.08) H (3.64) $\mathrm{N}$ (15.00) calculated $=\mathrm{C}(59.24) \mathrm{H}(3.67) \mathrm{N}$ (15.02).

$\mathrm{N}$-\{[3-(4-chlorophenyl)-4-oxo-3,4-dihydroquinazolin-2-yl]methyl $\}$ semicarbazone 3B(d-2) IR (KBr, cm-1) $3384(\mathrm{Ar}-\mathrm{H}), 1690$ (C=C), 1601 $(\mathrm{C}=\mathrm{N}), 1560(\mathrm{C}-\mathrm{C}), 1713(\mathrm{C}=\mathrm{O}), 3362(\mathrm{~N}-\mathrm{H}), 1670(\mathrm{C}=\mathrm{N}$ str of $\mathrm{NHN}=\mathrm{C})$; ${ }^{1} \mathrm{H}$ NMR $\left(300 \mathrm{MHz}, \mathrm{CDCl}_{3}, \mathrm{ppm}, \delta\right): 6.82(\mathrm{~m}, 4 \mathrm{H}, \mathrm{Ar}-\mathrm{H}), 7.53(\mathrm{~m}, 5 \mathrm{H}$, $\mathrm{ArH}), 2.69\left(\mathrm{~s}, 2 \mathrm{H}, \mathrm{CH}_{2}\right) 4.42(\mathrm{~s}, 1 \mathrm{H}, \mathrm{NH}), 11.39(\mathrm{~s}, 1 \mathrm{H}, \mathrm{CONH})$, anal. Calcd for; $\mathrm{C}_{24} \mathrm{H}_{20} \mathrm{Cl} \mathrm{N} \mathrm{N}_{5} \mathrm{O}_{2}$ (445.13) (\%): Found = C (64.60) H (4.48) N (15.69) calculated $=\mathrm{C}(64.65) \mathrm{H}(4.52) \mathrm{N}$ (15.71)

$\mathrm{N}-\{[3-(4-$ chlorophenyl)-4-oxo-3,4-dihydroquinazolin-2-yl]methyl $\}$ semicarbazone 3B(d-3) IR (KBr, cm$\left.{ }^{-1}\right) 3385(\mathrm{Ar}-\mathrm{H}), 1694$ (C=C), 1616 $(\mathrm{C}=\mathrm{N}), 1544(\mathrm{C}-\mathrm{C}), 1710(\mathrm{C}=0), 3356(\mathrm{~N}-\mathrm{H}), 1483(\mathrm{~N}-0), 1674$ (C=N str of $\mathrm{NHN}=\mathrm{C}) ;{ }^{1} \mathrm{H}$ NMR $\left(300 \mathrm{MHz}, \mathrm{CDCl}_{3}, \mathrm{ppm}, \delta\right): 6.70(\mathrm{~m}, 4 \mathrm{H}, \mathrm{Ar}-\mathrm{H}), 7.59$ (m, 5H, ArH), $2.60\left(\mathrm{~s}, 2 \mathrm{H}, \mathrm{CH}_{2}\right) 4.38(\mathrm{~s}, 1 \mathrm{H}, \mathrm{NH}), 11.34(\mathrm{~s}, 1 \mathrm{H}, \mathrm{CONH})$, anal. Calcd for; $\mathrm{C}_{24} \mathrm{H}_{19} \mathrm{ClN}_{6} \mathrm{O}_{4}$ (490.11) (\%): Found $=\mathrm{C}(58.70) \mathrm{H}(3.88)$ $\mathrm{N}(17.10)$ calculated $=\mathrm{C}(58.72) \mathrm{H}(3.90) \mathrm{N}(17.12)$.

$\mathrm{N}$-\{[3-(4-chlorophenyl)-4-oxo-3,4-dihydroquinazolin-2-yl]methyl\} semicarbazone 3B(d-4) IR (KBr, cm$\left.{ }^{-1}\right) 3380(\mathrm{Ar}-\mathrm{H}), 1692$ (C=C), 1617 $(\mathrm{C}=\mathrm{N}), 1552(\mathrm{C}-\mathrm{C}), 1712(\mathrm{C}=0), 3354(\mathrm{~N}-\mathrm{H}), 1674(\mathrm{C}=\mathrm{N}$ str of $\mathrm{NHN}=\mathrm{C})$; ${ }^{1} \mathrm{H}$ NMR $\left(300 \mathrm{MHz}, \mathrm{CDCl}_{3}, \mathrm{ppm}, \delta\right): 6.73(\mathrm{~m}, 4 \mathrm{H}, \mathrm{Ar}-\mathrm{H}), 7.55(\mathrm{~m}, 5 \mathrm{H}$, $\mathrm{ArH}), 2.91\left(\mathrm{~s}, 2 \mathrm{H}, \mathrm{CH}_{2}\right) 4.60(\mathrm{~s}, 1 \mathrm{H}, \mathrm{NH}), 11.38(\mathrm{~s}, 1 \mathrm{H}, \mathrm{CONH}), 1.35$ (s, 3H, $\left.\mathrm{CH}_{3}\right), 1.06\left(\mathrm{~s}, 3 \mathrm{H}, \mathrm{CH}_{3}\right), 1.26\left(\mathrm{~s}, 3 \mathrm{H}, \mathrm{CH}_{3}\right)$; anal. Calcd for; $\mathrm{C}_{23} \mathrm{H}_{21} \mathrm{ClN}_{5} \mathrm{O}_{2}$ (470.13) (\%): Found = C (63.49) H (4.84) N (16.08) calculated $=\mathrm{C}$ (63.52) H (4.87) N (16.10).

$\mathrm{N}$-\{[3-(4-chlorophenyl)-4-oxo-3,4-dihydroquinazolin-2-yl]methyl\}semicarbazone 3B(d-5) IR (KBr, cm $\left.{ }^{-1}\right) 3383(\mathrm{Ar}-\mathrm{H}), 1693(\mathrm{C}=\mathrm{C}), 1620$ $(\mathrm{C}=\mathrm{N}), 1563(\mathrm{C}-\mathrm{C}), 1723(\mathrm{C}=\mathrm{O}), 3359(\mathrm{~N}-\mathrm{H}), 1676(\mathrm{C}=\mathrm{N}$ str of $\mathrm{NHN}=\mathrm{C})$; ${ }^{1} \mathrm{H}$ NMR $\left(300 \mathrm{MHz}, \mathrm{CDCl}_{3}, \mathrm{ppm}, \delta\right): 6.76(\mathrm{~m}, 4 \mathrm{H}, \mathrm{Ar}-\mathrm{H}), 7.67(\mathrm{~m}, 5 \mathrm{H}, \mathrm{ArH})$, $2.88\left(\mathrm{~s}, 2 \mathrm{H}, \mathrm{CH}_{2}\right) 4.65(\mathrm{~s}, 1 \mathrm{H}, \mathrm{NH}), 11.47(\mathrm{~s}, 1 \mathrm{H}, \mathrm{CONH}), 1.38\left(\mathrm{~s}, 3 \mathrm{H}, \mathrm{CH}_{3}\right)$; anal. Calcd for; $\mathrm{C}_{26} \mathrm{H}_{29} \mathrm{~N}_{5} \mathrm{O}_{2}$ 298.16) (\%): Found = C (65.30) H (5.88) $\mathrm{N}(14.61)$ calculated $=\mathrm{C}(65.33) \mathrm{H}(5.90) \mathrm{N}(14.65)$.

$\mathrm{N}$-\{[3-(4-chlorophenyl)-4-oxo-3,4-dihydroquinazolin-2-yl]methyl\}semicarbazone 3B(d-6) IR (KBr, cm $\left.{ }^{-1}\right) 3384(\mathrm{Ar}-\mathrm{H}), 1656(\mathrm{C}=\mathrm{C}), 1626$ $(\mathrm{C}=\mathrm{N}), 1565(\mathrm{C}-\mathrm{C}), 1720(\mathrm{C}=\mathrm{O}), 3360(\mathrm{~N}-\mathrm{H}), 1669(\mathrm{C}=\mathrm{N}$ str of $\mathrm{NHN}=\mathrm{C})$, 1159 (C-O), 1225 (C-O-C); ${ }^{1} \mathrm{H}$ NMR $\left(300 \mathrm{MHz}, \mathrm{CDCl}_{3}, \mathrm{ppm}, \delta\right): 7.79$ (m, 4H, Ar-H), $7.60(\mathrm{~m}, 5 \mathrm{H}, \mathrm{ArH}), 2.73\left(\mathrm{~s}, 2 \mathrm{H}, \mathrm{CH}_{2}\right) 4.52(\mathrm{~s}, 1 \mathrm{H}, \mathrm{NH})$, 11.52 (s, 1H, CONH), $6.70(\mathrm{~m}, 3 \mathrm{H}, \mathrm{ArH}) 5.47(\mathrm{~s}, 1 \mathrm{H}, \mathrm{CH})$; anal. Calcd 
Table 1: Different aryl/cycloalkyl aldehyde or ketone used in the preparation of quinazolinone semicarbazone derivatives 3A-d (1-7), 3B-d (1-7), 3C-d (1-7)

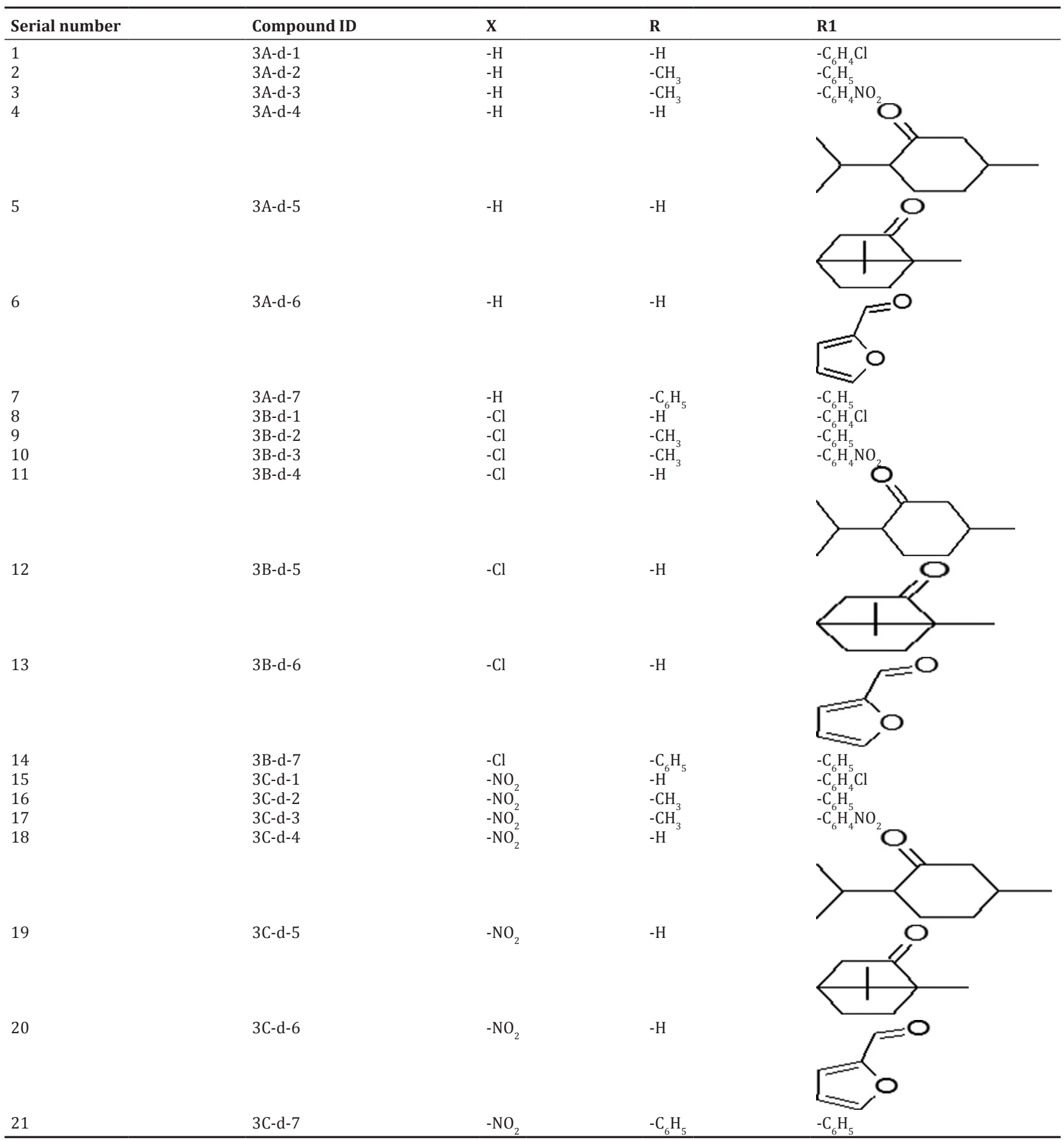

for; $\mathrm{C}_{21} \mathrm{H}_{16} \mathrm{ClN}_{5} \mathrm{O}_{3}$ (421.09) (\%): Found = C (59.72) H (3.80) N (16.57) calculated $=\mathrm{C}(59.79) \mathrm{H}(3.82) \mathrm{N}(16.60)$.

$\mathrm{N}$-\{[3-(4-chlorophenyl)-4-oxo-3,4-dihydroquinazolin-2-yl]methyl\}semicarbazone $3 \mathrm{~B}(\mathrm{~d}-7)$ IR $\left(\mathrm{KBr}, \mathrm{cm}^{-1}\right) 3373(\mathrm{Ar}-\mathrm{H}), 1655(\mathrm{C}=\mathrm{C})$, 1608 (C=N), 1559 (C-C), 1709 (C=0), 3357 (N-H), 1669 (C=N str of $\mathrm{NHN}=\mathrm{C}),{ }^{1} \mathrm{H}$ NMR $\left(300 \mathrm{MHz}, \mathrm{CDCl}_{3}, \mathrm{ppm}, \delta\right): 7.83(\mathrm{~m}, 4 \mathrm{H}, \mathrm{Ar}-\mathrm{H}), 7.43$ (m, 5H, ArH), $2.72\left(\mathrm{~s}, 2 \mathrm{H}, \mathrm{CH}_{2}\right) 3.45(\mathrm{~s}, 1 \mathrm{H}, \mathrm{NH}), 11.40(\mathrm{~s}, 1 \mathrm{H}, \mathrm{CONH}), 7.92$ $(\mathrm{m}, 5 \mathrm{H}, \mathrm{ArH}) 6.49(\mathrm{~m}, 5 \mathrm{H}, \mathrm{ArH})$; anal. Calcd for; $\mathrm{C}_{29} \mathrm{H}_{22} \mathrm{ClN}_{5} \mathrm{O}_{2}$ (507.14) (\%): Found $=\mathrm{C}(68.51) \mathrm{H}(4.33) \mathrm{N}(13.77)$ calculated $=\mathrm{C}(68.57)$ H (4.37) N (13.79).
$\mathrm{N}$-\{[3-(4-nitrophenyl)-4-oxo-3,4-dihydroquinazolin-2-yl]methyl\}semicarbazone 3C(d-1) IR (KBr, cm $\left.{ }^{-1}\right) 3382(\mathrm{Ar}-\mathrm{H}), 1686(\mathrm{C}=\mathrm{C}), 1606$ $(\mathrm{C}=\mathrm{N}), 1552(\mathrm{C}-\mathrm{C}), 1725$ (C=0), $3360(\mathrm{~N}-\mathrm{H}), 1091(\mathrm{Ar}-\mathrm{Cl}), 1665$ (C=N str of $\mathrm{NHN}=\mathrm{C}$ ); ${ }^{1} \mathrm{H}$ NMR (300 MHz, $\left.\mathrm{CDCl}_{3}, \mathrm{ppm}, \delta\right): 6.71(\mathrm{~m}, 4 \mathrm{H}, \mathrm{Ar}-\mathrm{H}), 7.24$ (m, 5H, ArH), $2.75\left(\mathrm{~s}, 2 \mathrm{H}, \mathrm{CH}_{2}\right) 4.54(\mathrm{~s}, 1 \mathrm{H}, \mathrm{NH}), 11.35(\mathrm{~s}, 1 \mathrm{H}, \mathrm{CONH})$, anal. Calcd for; $\mathrm{C}_{23} \mathrm{H}_{17} \mathrm{ClN}_{6} \mathrm{O}_{4}$ 476.01) (\%): Found = C (57.90) H (3.60) $\mathrm{N}$ (17.59) calculated $=\mathrm{C}$ (57.93) H (3.59) N (17.62).

$\mathrm{N}$-\{[3-(4-nitrophenyl)-4-oxo-3, 4-dihydroquinazolin-2-yl] methyl $\}$ semicarbazone 3C(d-2) IR (KBr, cm$\left.{ }^{-1}\right) 3382(\mathrm{Ar}-\mathrm{H}), 1693(\mathrm{C}=\mathrm{C}), 1606$ $(\mathrm{C}=\mathrm{N}), 1563(\mathrm{C}-\mathrm{C}), 1715(\mathrm{C}=0), 3360(\mathrm{~N}-\mathrm{H}), 1674(\mathrm{C}=\mathrm{N}$ str of $\mathrm{NHN}=\mathrm{C})$; 
Table 2: Physical properties of the final synthesized quinazolinone semicarbazone derivatives

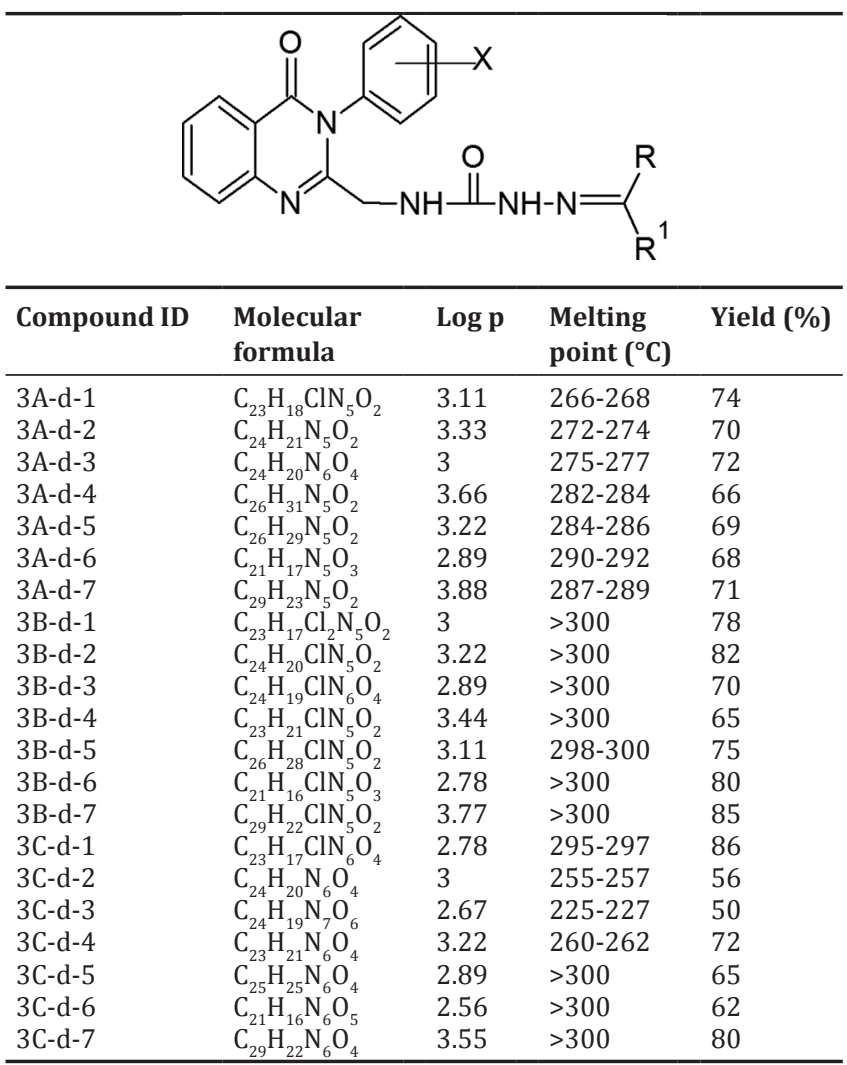

${ }^{1} \mathrm{H}$ NMR (300 MHz, $\left.\mathrm{CDCl}_{3}, \mathrm{ppm}, \delta\right): 6.83(\mathrm{~m}, 4 \mathrm{H}, \mathrm{Ar}-\mathrm{H}), 7.54(\mathrm{~m}, 5 \mathrm{H}$, $\mathrm{ArH}), 2.68\left(\mathrm{~s}, 2 \mathrm{H}, \mathrm{CH}_{2}\right) 4.40$ (s, 1H, NH), 11.35 (s, 1H, CONH), anal. Calcd for; $\mathrm{C}_{24} \mathrm{H}_{20} \mathrm{~N}_{6} \mathrm{O}_{4}$ (456.15) (\%): Found = C (63.11) H (4.40) N (18.44) calculated $=\mathrm{C}(63.15) \mathrm{H}(4.42) \mathrm{N}(18.41)$

$\mathrm{N}-\{[3-(4-$-nitrophenyl)-4-oxo-3, 4-dihydroquinazolin-2-yl] methyl $\}$ semicarbazone 3C(d-3) IR (KBr, cm$\left.{ }^{-1}\right) 3383(\mathrm{Ar}-\mathrm{H}), 1699$ (C=C), 1619 $(\mathrm{C}=\mathrm{N}), 1554(\mathrm{C}-\mathrm{C}), 1720(\mathrm{C}=0), 3358(\mathrm{~N}-\mathrm{H}), 1488(\mathrm{~N}-\mathrm{O}), 1679$ (C=N str of NHN=C); ${ }^{1} \mathrm{H}$ NMR (300 MHz, CDCl ${ }^{\prime}$ ppm, $\left.\delta\right): 6.73(\mathrm{~m}, 4 \mathrm{H}, \mathrm{Ar}-\mathrm{H}), 7.58$ (m, 5H, ArH), $2.63\left(\mathrm{~s}, 2 \mathrm{H}, \mathrm{CH}_{2}\right) 4.40(\mathrm{~s}, 1 \mathrm{H}, \mathrm{NH}), 11.44(\mathrm{~s}, 1 \mathrm{H}, \mathrm{CONH})$, anal. Calcd for; $\mathrm{C}_{24} \mathrm{H}_{19} \mathrm{~N}_{7} \mathrm{O}_{6}$ (501.13) (\%): Found = C (57.45) H (3.80) $\mathrm{N}$ (19.52) calculated $=\mathrm{C}(57.48) \mathrm{H}(3.82) \mathrm{N}(19.55)$.

$\mathrm{N}$-\{[3-(4-nitrophenyl)-4-oxo-3, 4-dihydroquinazolin-2-yl] methyl\} semicarbazone 3C(d-4) IR ( $\left.\mathrm{KBr}, \mathrm{cm}^{-1}\right) 3384(\mathrm{Ar}-\mathrm{H}), 1691$ (C=C), 1620 $(\mathrm{C}=\mathrm{N}), 1559(\mathrm{C}-\mathrm{C}), 1709(\mathrm{C}=\mathrm{O}), 3350(\mathrm{~N}-\mathrm{H}), 1670(\mathrm{C}=\mathrm{N}$ str of NHN=C); ${ }^{1} \mathrm{H}$ NMR $\left(300 \mathrm{MHz}, \mathrm{CDCl}_{3}, \mathrm{ppm}, \delta\right): 6.69(\mathrm{~m}, 4 \mathrm{H}, \mathrm{Ar}-\mathrm{H}), 7.51$ (m, 5H, ArH), $2.89\left(\mathrm{~s}, 2 \mathrm{H}, \mathrm{CH}_{2}\right) 4.55(\mathrm{~s}, 1 \mathrm{H}, \mathrm{NH}), 11.33(\mathrm{~s}, 1 \mathrm{H}, \mathrm{CONH}), 1.30\left(\mathrm{~s}, 3 \mathrm{H}, \mathrm{CH}_{3}\right)$, $1.12\left(\mathrm{~s}, 3 \mathrm{H}, \mathrm{CH}_{3}\right), 1.21\left(\mathrm{~s}, 3 \mathrm{H}, \mathrm{CH}_{3}\right)$; anal. Calcd for; $\mathrm{C}_{23} \mathrm{H}_{21} \mathrm{~N}_{6} \mathrm{O}_{4}(481.16)$ (\%): Found $=\mathrm{C}(62.01) \mathrm{H}(4.75) \mathrm{N}(18.87)$ calculated $=\mathrm{C}(62.01)$ $\mathrm{H}(4.75) \mathrm{N}$ (18.87).

$\mathrm{N}$-\{[3-(4-nitrophenyl)-4-oxo-3, 4-dihydroquinazolin-2-yl]methyl\}semicarbazone 3C(d-5) IR (KBr, cm$\left.{ }^{-1}\right) 3379(\mathrm{Ar}-\mathrm{H}), 1687(\mathrm{C}=\mathrm{C}), 1610$ $(\mathrm{C}=\mathrm{N}), 1553(\mathrm{C}-\mathrm{C}), 1713(\mathrm{C}=\mathrm{O}), 3349(\mathrm{~N}-\mathrm{H}), 1669$ (C=N str of NHN=C); ${ }^{1} \mathrm{H} \mathrm{NMR}\left(300 \mathrm{MHz}, \mathrm{CDCl}_{3}, \mathrm{ppm}, \delta\right): 6.71(\mathrm{~m}, 4 \mathrm{H}, \mathrm{Ar}-\mathrm{H}), 7.62(\mathrm{~m}, 5 \mathrm{H}, \mathrm{ArH})$, $2.89\left(\mathrm{~s}, 2 \mathrm{H}, \mathrm{CH}_{2}\right) 4.68(\mathrm{~s}, 1 \mathrm{H}, \mathrm{NH}), 11.41(\mathrm{~s}, 1 \mathrm{H}, \mathrm{CONH}), 1.42\left(\mathrm{~s}, 3 \mathrm{H}, \mathrm{CH}_{3}\right)$; anal. Calcd for; $\mathrm{C}_{25} \mathrm{H}_{25} \mathrm{~N}_{6} \mathrm{O}_{4}$ (473.50) (\%): Found = C (63.39) $\mathrm{H}(5.30)$ $\mathrm{N}$ (17.71) calculated $=\mathrm{C}(63.41) \mathrm{H}(5.32) \mathrm{N}$ (17.75).

$\mathrm{N}-\{[3-(4-$-nitrophenyl)-4-oxo-3, 4-dihydroquinazolin-2-yl] methyl\}semicarbazone 3C(d-6) IR (KBr, cm $\left.{ }^{-1}\right) 3388(\mathrm{Ar}-\mathrm{H}), 1659$ (C=C), $1620(\mathrm{C}=\mathrm{N}), 1555(\mathrm{C}-\mathrm{C}), 1727(\mathrm{C}=\mathrm{O}), 3366(\mathrm{~N}-\mathrm{H}), 1668$ (C=N str of
$\mathrm{NHN}=\mathrm{C}$ ), 1169 (C-0), 1227 (COC); ${ }^{1} \mathrm{H}$ NMR (300 MHz, CDCl, ppm, $\delta$ ): 7.69 (m, 4H, ArH), 7.65 (m, 5H, ArH), 2.77 (s, 2H, CH $) 4.42(\mathrm{~s}, 1 \mathrm{H}, \mathrm{NH})$, $11.42(\mathrm{~s}, 1 \mathrm{H}, \mathrm{CONH}), 6.73(\mathrm{~m}, 3 \mathrm{H}, \mathrm{ArH}) 5.41(\mathrm{~s}, 1 \mathrm{H}, \mathrm{CH})$; anal. Calcd for; $\mathrm{C}_{21} \mathrm{H}_{16} \mathrm{~N}_{6} \mathrm{O}_{5}$ (432.11) (\%): Found $=\mathrm{C}(58.30) \mathrm{H}(3.70) \mathrm{N}$ (19.42) calculated $=\mathrm{C}(58.33) \mathrm{H}(3.73) \mathrm{N}(19.44)$.

$\mathrm{N}$-\{[3-(4-nitrophenyl)-4-oxo-3, 4-dihydroquinazolin-2-yl] methyl\}semicarbazone 3C (d-7) IR ( $\left.\mathrm{KBr}, \mathrm{cm}^{-1}\right) 3377$ (Ar-H), 1665 (C=C), 1600 $(\mathrm{C}=\mathrm{N}), 1569(\mathrm{C}-\mathrm{C}), 1719(\mathrm{C}=0), 3347(\mathrm{~N}-\mathrm{H}), 1670(\mathrm{C}=\mathrm{N}$ str of $\mathrm{NHN}=\mathrm{C})$, ${ }^{1} \mathrm{H}$ NMR $\left(300 \mathrm{MHz}, \mathrm{CDCl}_{3}, \mathrm{ppm}, \delta\right): 7.73(\mathrm{~m}, 4 \mathrm{H}, \mathrm{Ar}-\mathrm{H}), 7.42(\mathrm{~m}, 5 \mathrm{H}$, $\mathrm{ArH}), 2.70$ (s, 2H, $\mathrm{CH}_{2}$ ) 3.41 (s, 1H, NH), 11.37 (s, 1H, CONH), $7.91(\mathrm{~m}$, $5 \mathrm{H}, \mathrm{ArH}) 6.59$ (m, 5H, ArH); anal. Calcd for; $\mathrm{C}_{29} \mathrm{H}_{22} \mathrm{~N}_{6} \mathrm{O}_{4}$ (518.17) (\%): Found $=\mathrm{C}(67.15) \mathrm{H}(4.26) \mathrm{N}$ (16.20) calculated $=\mathrm{C}(67.17) \mathrm{H}(4.28)$ $\mathrm{N}(16.21)$.

\section{Anticonvulsant screening \\ Animals}

Albino mice of either sex weighing between 25-30 g were used in this study. All albino mice employed in this study is approved by the Institutional Animal Ethics Committee of NBRI, Lucknow and carried out as per CPCSEA guidelines. The animals were kept in large spacious hygienic cages during the course of the experimental period. The animals had free access to standard commercial diet and water ad libitum and were kept in rooms maintained at $22 \pm 1^{\circ} \mathrm{C}$ with 12 hrs light-dark cycle. The animals were divided into three groups of 10 animals each: Group I: Control group (distilled water treated). Group II: Test group (were dissolved in polyethylene glycol-400 and 30, 100, $300 \mathrm{mg} / \mathrm{kg}$ i.p. doses), Group III: Standard group, on reference drug (diazepam, $10 \mathrm{mg} / \mathrm{kg}$ i.p. phenytoin $30 \mathrm{mg} / \mathrm{kg}$ i.p.). All the drugs were administered 30 minutes before the administration of strychnine $(1 \mathrm{mg} / \mathrm{kg}$, i.p.) thiosemicarbazide $(20 \mathrm{mg} / \mathrm{kg}$, s.c.) and 4-aminopyridine $(13.3 \mathrm{mg} / \mathrm{kg}$, s.c.). The anticonvulsant screening of the final compounds was done according to the protocols of the anticonvulsant drug development program [48].

\section{Procedure}

\section{Strychnine induced model}

Mice of either sex with a weight of 25-30 g were treated with the test compounds or the standards (eg., diazepam $10 \mathrm{mg} / \mathrm{kg}$ ip.) by an oral or intraperitoneal administration. Controls received the vehicle only. 30 minutes prior treatment with a subcutaneous dose of $1 \mathrm{mg} / \mathrm{kg}$ strychnine, test compounds in doses 30, 100; $300 \mathrm{mg} / \mathrm{kg}$ i.p. was injected. The occurrence of clonic seizures, tonic seizures, and death or recovery was recorded after $0.5 \mathrm{hr}, 1 \mathrm{hr}, 2 \mathrm{hrs}$ and $4 \mathrm{hrs}$, respectively [49].

\section{Thiosemicarbazide induced model}

Mice of either sex with a weight of 25-30 g were treated with the test compounds or the standard (e.g., diazepam $10 \mathrm{mg} / \mathrm{kg}$ i.p.) by the oral or intraperitoneal administration. Controls received the vehicle only. 30 minutes prior treatment with a subcutaneous dose of $20 \mathrm{mg} / \mathrm{kg}$ thiosemicarbazide, test compounds in doses $30,100,300 \mathrm{mg} / \mathrm{kg}$ i.p. was injected. The occurrence of clonic seizures, tonic seizures, and death or recovery was recorded after $0.5 \mathrm{hr}, 1 \mathrm{hr}, 2 \mathrm{hrs}$ and $4 \mathrm{hrs}$, respectively [50].

\section{4-amino pyridine induced model}

Mice of either sex weighing 25-30 g will allow acclimatizing with free access to food and water for a 24-hr period before testing. Test drugs will administer at a dose of $30,100,300 \mathrm{mg} / \mathrm{kg}$ body weight intraperitoneally (i.p.), 30 minutes prior to subcutaneous injection of 4-aminopyridine at a dose of $13.3 \mathrm{mg} / \mathrm{kg}$. Controls treated with 4-aminopyridine only exhibit characteristic behavioral signs, such as hyperreactivity, trembling, intermitted forelimb/hindlimb clones followed by hind limb extension, tonic seizures, and death. The standard drug phenytoin at a dose of $30 \mathrm{mg} / \mathrm{kg}$ body weight was taken for comparison [51]. 
Neurotoxicity (NT) screening

The activity of the drugs interfering with motor coordination was checked by the rotarod test. The mice will train to stay on an accelerating rotarod that rotates at 6 revolutions per minute. Trained animals were given ip injection of the test compounds in doses of $30,100,300 \mathrm{mg} / \mathrm{kg}$. The rod diameter was $3.2 \mathrm{~cm}$. NT indicated by the inability of the animal to maintain equilibrium on the rotarod for at least 1 minute in each of three trials. The dose, at which the animals were unable to grasp the rotarod, will determine. All the results were reported in Table 3.

\section{RESULTS AND DISCUSSIONS}

\section{Chemistry}

A series of new quinazolinone derivatives 3A-d (1-7), 3B-d (1-7), and 3C-d (1-7) have been synthesized using appropriate routes. All newly synthesized compounds were characterized on the basis of their m.p, Rf value (data are shown in Table 2), Fourier transform infrared, ${ }^{1} \mathrm{H}$ NMR, and elemental analysis. From the structural investigation, IR spectra showed the stretching frequency range between 1580 and $1620 / \mathrm{cm}$, which showed the presence of imine linkage and also the absence of $-\mathrm{NH}_{2}$ peak for the synthesized quinazolinone semicarbazone derivatives. Dependent substitution of double bonded nitrogen group of imine $\mathrm{C}=\mathrm{N}$ could be the reason for the characteristic absorption close to the carbonyl $\mathrm{C}=0$ of amide $\left(1632-1685 \mathrm{~cm}^{-1}\right)$ or $\mathrm{C}=\mathrm{C}$ of alkene $(1600-1680 / \mathrm{cm})$ double bond stretching region. ${ }^{1} \mathrm{H}-\mathrm{NMR}$ spectra give a characteristic proton resonance shifts for all the synthesized quinazolinone semicarbazone derivatives, which ensured the existence of aromatic, amine, amide, and imine protons. Almost all the synthesized analog showed potent anticonvulsive activity.

\section{Design}

The conformational analysis of the older generation clinically active anticonvulsant drugs such as phenytoin, phenobarbitone, carbamazepine, lamotrigine, rufinamide, and remacemide led to the proposal of a general model for anticonvulsant activity comprising of two aromatic rings or they are equivalent in a favored orientation and the third region containing a hydrogen bond-forming functional groups in terms of interaction at the binding site as proposed by Dimmock et al. [43]. All the synthesized compounds comprise these essential pharmacophoric requirements that are important for good anticonvulsant activity.

\section{Pharmacology}

Quinazolinone heterocycles are the attractive scaffold as anticonvulsant agents as well as various CNS activities [52,53]. We have designed a novel quinazolinone semicarbazones. In the pharmacological study, we have investigated anticonvulsant activity as well as the NT. All the synthesized compounds were screened for their anticonvulsant activity using various chemical induced convulsion models using strychnine, thiosemicarbazide and 4-aminopyridine to induced convulsion, diazepam and phenytoin were used as the standard drug at the dose of $30,100,300 \mathrm{mg} / \mathrm{kg}$ b.w. anticonvulsant activity and NT data for the semicarbazones of quinazolinone derivatives 3A-d (1-7), 3B-d (1-7), 3C-d (1-7) are given in Table 3, and most of the compounds showed mild to moderate anticonvulsant activity. The analogs 3A-d-5, 3B-d-5, and $3 \mathrm{C}-\mathrm{d}-5$ were active at $30 \mathrm{mg} / \mathrm{kg}$ and $100 \mathrm{mg} / \mathrm{kg}$ only at $0.5 \mathrm{~h}$ and $1 \mathrm{~h}$, indicating that they have the rapid onset of action and shorter duration of action and were exhibit moderate anticonvulsant activity. The compounds 3A-d-4, 3B-d-4, 3C-d-4 were observed to be most active for anticonvulsant activity. All the compounds showed activity against chemo shock method pinpointing their capability to prevent seizure spread.

\section{SAR}

It also showed that a substituted aromatic ring in position 3 is significant for anticonvulsant activity. Various N-1(substituted-N-4[(4oxo-3-phenyl-3, 4-dihydro-quinazoline-2-ylmethyl) semicarbazones derivatives 3A-d (1-7), 3B-d (1-7), 3C-d (1-7) were synthesized to establish the pharmacophoric substituents, responsible for the activity.

Table 3: Anticonvulsant evaluation and neurotoxicity screenings of new quinazolinone semicarbazone derivatives 3A-d (1-7), 3B-d (1-7), 3C-d (1-7) in the strychnine, thiosemicarbazide, 4-aminopyridine induce model after intraperitoneal injection in mice

\begin{tabular}{|c|c|c|c|c|c|c|c|c|c|c|c|}
\hline \multirow[t]{2}{*}{ Time to peak effect } & \multicolumn{3}{|c|}{$\begin{array}{l}\text { Strychnine induced } \\
\text { convulsion }\end{array}$} & \multicolumn{3}{|c|}{$\begin{array}{l}\text { Thiosemicarbazide } \\
\text { induced convulsion }\end{array}$} & \multicolumn{3}{|c|}{$\begin{array}{l}\text { 4-amino pyridine } \\
\text { induced convulsion }\end{array}$} & \multicolumn{2}{|c|}{ Neurotoxicity screen } \\
\hline & $0.5 \mathrm{~h}$ & $1 \mathrm{~h}$ & $2 \mathrm{~h}$ & $0.5 \mathrm{~h}$ & $1 \mathrm{~h}$ & $2 \mathrm{~h}$ & $0.5 \mathrm{~h}$ & $1 \mathrm{~h}$ & $2 \mathrm{~h}$ & $0.5 \mathrm{~h}$ & $4 \mathrm{~h}$ \\
\hline Controls & - & - & - & - & - & - & - & - & - & - & - \\
\hline Compound ID & & & & & & & & & & & \\
\hline $3 A-d-1$ & 30 & - & - & 30 & - & - & 30 & - & & 100 & - \\
\hline $3 A-d-2$ & 30 & - & - & 30 & - & - & 30 & - & - & 100 & - \\
\hline $3 A-d-3$ & 30 & - & - & 30 & - & - & - & - & - & 100 & - \\
\hline $3 A-d-4$ & 300 & 100 & 100 & 300 & 100 & 30 & 100 & 30 & - & 300 & 300 \\
\hline $3 A-d-5$ & 30 & 100 & - & 30 & 100 & - & 30 & 30 & - & 300 & - \\
\hline $3 A-d-6$ & 30 & 30 & - & - & - & - & - & - & - & 30 & 30 \\
\hline $3 A-d-7$ & 30 & - & - & - & - & - & - & - & - & 300 & - \\
\hline $3 B-d-1$ & 30 & - & - & 100 & - & - & 30 & - & - & 30 & - \\
\hline $3 B-d-2$ & 30 & - & - & 30 & - & - & 30 & - & - & 30 & - \\
\hline $3 B-d-3$ & 30 & - & - & 30 & - & - & - & - & - & 100 & - \\
\hline $3 B-d-4$ & 300 & 100 & 100 & 300 & 100 & 30 & 100 & 100 & 30 & 300 & 300 \\
\hline $3 B-d-5$ & 30 & 30 & - & 100 & 30 & - & 30 & 30 & - & 100 & - \\
\hline 3B-d-7 & 30 & - & - & - & - & - & - & - & - & 100 & - \\
\hline $3 C-d-1$ & 30 & - & - & 30 & - & - & 30 & - & - & 100 & - \\
\hline $3 C-d-2$ & 30 & - & - & 30 & - & - & 30 & - & - & 30 & - \\
\hline $3 C-d-3$ & 30 & - & - & 30 & - & - & - & - & - & 100 & - \\
\hline $3 C-d-4$ & 300 & 100 & 100 & 300 & 100 & 30 & 100 & 30 & 30 & 300 & 300 \\
\hline $3 C-d-5$ & 100 & 30 & - & 100 & 100 & - & 30 & 30 & - & 30 & - \\
\hline $3 C-d-6$ & 30 & 30 & - & 30 & - & - & - & - & - & 30 & 100 \\
\hline $3 C-d-7$ & 30 & - & - & - & - & - & - & - & - & 30 & - \\
\hline Diazepam (mg/kg) & 10 & 10 & 10 & 10 & 10 & 10 & - & - & - & & \\
\hline Phenytoin (mg/kg) & & & & & & & 30 & 30 & 30 & & \\
\hline
\end{tabular}

$\mathrm{n}=10$, test compounds were suspended in polyethylene glycol and doses of 30,100, $300 \mathrm{mg} / \mathrm{kg}$ were administered through intraperitoneal (i.p.) injection in mice. The figures in the table indicate the dose in $\mathrm{mg} / \mathrm{kg}$ at which bioactivity was observed in a majority of the animals. The dash (-) indicates an absence of activity at maximum dose administered (300 mg/kg), In neurotoxicity screen the figure indicate the dose at which no neurotoxicity was observed and the dash (-) indicates compounds was not tested 


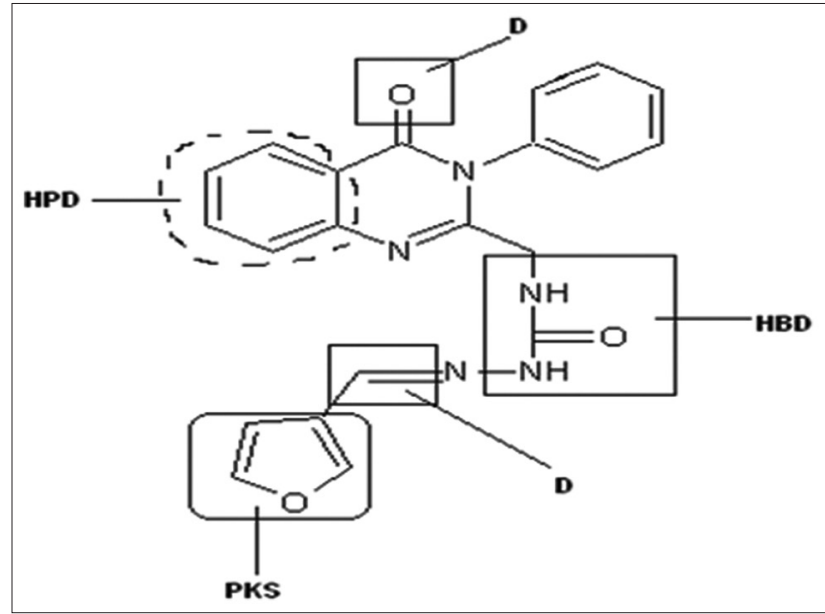

Fig. 1: Quinazolinone pharmacophore

The aryl/cyclohexyl ring acts as a lipophilic domain, $\mathrm{C}=\mathrm{O}$ group acts as electron donor, $\mathrm{NH}$ groups act as hydrogen bonding domain, and the aryl substituent acts as the distal hydrophobic center Fig. 1. Thus, it may be stated that compounds 3A-d (1-7), 3B-d (1-7), 3C-d (1-7) fulfill the essential pharmacophoric requirements for anticonvulsant activity.

Compounds 3A-d-5, 3B-d-5, 3C-d-5 displayed moderate and compounds 3A-d-4, 3B-d-4, 3C-d-4 most protection in chemo shock models study and supported the pharmacophoric character of cyclohexyl moiety for anticonvulsant activity. This observation supports the fact that substitution on the aryl ring by halogen led to a number of semicarbazones with low $\mathrm{ED}_{50}$ value and high protective index value. This observation also indicated the role of electronic factors affecting anticonvulsant activity.

\section{CONCLUSION}

In this paper, we have attempted to design and synthesized novel quinazolinone derivatives that exhibit anticonvulsant activity. The results obtained revealed that numbers of novel quinazolinone derivatives effective in chemical induce (chemo shock) model, compounds 3A-d-4, 3B-d-4, 3C-d-4 showed the most active while 3A-d-5, 3B-d-5, 3C-d-5 moderate activity and remaining compounds showed mild activity. This study provides the broad-spectrum anticonvulsant activity of substituted quinazolinone semicarbazones that are comparatively higher or equipotent to the currently available drugs in the comparison tests. Overall, the synthesized compounds emerged as more active and less neurotoxic derivatives.

\section{ACKNOWLEDGMENTS}

The authors would like to express their gratitude to Late Prof. S.N. Pandeya for the research guidance he has provided during this project. Authors are also thanks to head, sophisticated analytical instrumental facility department, Central Drug Research Institute (CDRI) for providing spectroscopic analysis facilities. One of the authors is thankful to the director, Saroj Institute of technology and management, Lucknow, India, for providing necessary laboratory facilities and also to the Dr. Chv Rao, Scientist in Pharmacology, Pharmacognosy \& Ethnopharmacology Division, National Botanical Research Institute, Lucknow, Uttar Pradesh, for providing facilities to performing the anticonvulsant activity.

\section{REFERENCES}

1. Ram VJ, Farhanullah, Tripathi BK, Srivastava AK. Synthesis and antihyperglycemic activity of suitably functionalized 3H-quinazolin-4ones. Bioorg Med Chem 2003;11(11):2439-44.

2. Dandia A, Singh R, Sarawgi P. Green chemical multi-component onepot synthesis of fluorinated 2,3-disustitued quinazolin-4(3H)-ones under solvent free conditions and their anti-fungal activity. J Fluor Chem 2004;125(12):1835-40.

3. Carl GF, Smith ML. Phenytoin-folate interactions: Differing effects of the sodium salt and the free acid of phenytoin. Epilepsia 1992;33(2):372-5.

4. Kwan P, Brodie MJ. Phenobarbital for the treatment of epilepsy in the $21^{\text {st }}$ century: A critical review. Epilepsia 2004;45(9):1141-9.

5. Shorvon SD. Drug treatment of epilepsy in the century of the ILAE: The second 50 years, 1959-2009. Epilepsia 2009;50 Suppl 3:93-130.

6. Foster AC, Kemp JA. Glutamate- and GABA-based CNS therapeutics. Curr Opin Pharmacol 2006;6(1):7-17.

7. Mazza M, Della Marca G, Di Nicola M, Martinotti G, Pozzi G, Janiri L, et al. Oxcarbazepine improves mood in patients with epilepsy. Epilepsy Behav 2007;10(3):397-401.

8. Rho JM, Donevan SD, Rogawski MA. Barbiturate-like actions of the propanediol dicarbamates felbamate and meprobamate. J Pharmacol Exp Ther 1997;280(3):1383-91.

9. Coyle JT, Leski M, Morrison JH. The diverse roles of L-glutamic acid in brain signal transduction. In: Davis KL, Charney D, Coyle JT, Nemeroff C, editors. Neuropsychopharmacology: The Fifth Generation of Progress. Philadelphia, PA: Lippincott, Williams \& Wilkins; 2002. p. 71-90.

10. Hassel B, Dingledine R. Glutamate. In: Siegel GJ, Albers RW, Brady ST, Price DL, editors. Basic Neurochemistry Molecular, Cellular, and Medical Aspects. $7^{\text {th }}$ ed., Ch. 15. Burlington, MA: Elsevier Academic Press; 2006. p. 267-90.

11. Ascher P, Nowak L. Quisqualate-and kainate-activated channels in mouse central neurones in culture. J Physiol 1988;399:227-45.

12. Collingridge GL, Lester RA. Excitatory amino acid receptors in the vertebrate central nervous system. Pharmacol Rev 1989;41(2):143-210.

13. Bliss TV, Collingridge GL. A synaptic model of memory: Long-term potentiation in the hippocampus. Nature 1993;361(6407):31-9.

14. Collingridge GL, Bliss TV. Memories of NMDA receptors and LTP. Trends Neurosci 1995;18(2):54-6.

15. Collingridge GL, Singer W. Excitatory amino acid receptors and synaptic plasticity. Trends Pharmacol Sci 1990;11(1):290-6.

16. Danysz W, Parsons, GG, Bresink I, Quack G. Glutamate in CNS disorders: A revived target for drug development. Drug News Perspect 1995;8:261-77.

17. Dingledine R, Borges K, Bowie D, Traynelis SF. The glutamate receptor ion channels. Pharmacol Rev 1999;51(1):7-61.

18. Gill SS, Pulido OM, Mueller RW, McGuire PF. Molecular and immunochemical characterization of the ionotropic glutamate receptors in the rat heart. Brain Res Bull 1998;46(5):429-34.

19. Hashimoto K, Shimizu E, Iyo M. Dysfunction of glia-neuron communication in the pathophysiology of schizophrenia. Curr Psychiatry Rev 2005;1:151-63.

20. Hashimoto K, Hattori E. Part II. Candidate gene and models. 4. Neurotransmission. In: Sawa A, McInnis MG, editors. Neurogenetics of Psychiatric Disorders. New York: Informa Healthcare; 2007. p. 81-100.

21. Nadler JV. Plasticity of glutamate synaptic mechanisms. In: Noebels JL, Avoli M, Rogawski MA, Olsen RW, Delgado-Escueta AV, editors. Jasper's Basic Mechanisms of the Epilepsies. th $^{\text {th }}$ ed. Bethesda, MD: US: National Center for Biotechnology Information; 2012.

22. Traynelis SF, Wollmuth LP, McBain CJ, Menniti FS, Vance KM, Ogden KK, et al. Glutamate receptor ion channels: Structure, regulation, and function. Pharmacol Rev 2010;62(3):405-96.

23. Rogawski MA. Revisiting AMPA receptors as an antiepileptic drug target. Epilepsy Curr 2011;11(2):56-63.

24. Lerma J, Paternain AV, Rodríguez-Moreno A, López-García JC. Molecular physiology of kainate receptors. Physiol Rev 2001;81(3):971-98.

25. Bleakman D. Kainate receptor pharmacology and physiology. Cell Mol Life Sci 1999;56(7-8):558-66.

26. Semyanov A, Kullmann DM. Kainate receptor-dependent axonal depolarization and action potential initiation in interneurons. Nat Neurosci 2001;4(7):718-23.

27. Ben-Ari Y, Cossart R. Kainate, a double agent that generates seizures: Two decades of progress. Trends Neurosci 2000;23(11):580-7.

28. Mulle C, Sailer A, Pérez-Otaño I, Dickinson-Anson H, Castillo PE, Bureau I, et al. Altered synaptic physiology and reduced susceptibility to kainate-induced seizures in GluR6-deficient mice. Nature 1998;392(6676):601-5

29. Vignes M, Bleakman D, Lodge D, Collingridge GL. The synaptic activation of the GluR5 subtype of kainate receptor in area CA3 of the rat hippocampus. Neuropharmacology 1997;36(11-12):1477-81.

30. Li H, Rogawski MA. GluR5 kainate receptor mediated synaptic 
transmission in rat basolateral amygdala in vitro. Neuropharmacology 1998;37(10-11):1279-86

31. Wu LJ, Zhao MG, Toyoda H, Ko SW, Zhuo M. Kainate receptormediated synaptic transmission in the adult anterior cingulate cortex. J Neurophysiol 2005;94(3):1805-13.

32. Koga K, Sim SE, Chen T, Wu LJ, Kaang BK, Zhuo M. Kainate receptor-mediated synaptic transmissions in the adult rodent insular cortex. J Neurophysiol 2012;108(7):1988-98.

33. Cossart R, Esclapez M, Hirsch JC, Bernard C, Ben-Ari Y. GluR5 kainate receptor activation in interneurons increases tonic inhibition of pyramidal cells. Nat Neurosci 1998;1(6):470-8

34. Wondolowski J, Frerking M. Subunit-dependent postsynaptic expression of kainate receptors on hippocampal interneurons in area CA1. J Neurosci 2009;29(2):563-74.

35. Christensen JK, Paternain AV, Selak S, Ahring PK, Lerma J. A mosaic of functional kainate receptors in hippocampal interneurons. J Neurosci 2004;24(41):8986-93.

36. Aroniadou-Anderjaska V, Pidoplichko VI, Figueiredo TH, AlmeidaSuhett CP, Prager EM, Braga MF. Presynaptic facilitation of glutamate release in the basolateral amygdala: A mechanism for the anxiogenic and seizurogenic function of GluK1 receptors. Neuroscience 2012;221:157-69.

37. Smolders I, Bortolotto ZA, Clarke VR, Warre R, Khan GM, O'Neill MJ, et al. Antagonists of GLU(K5)-containing kainate receptors prevent pilocarpine-induced limbic seizures. Nat Neurosci 2002;5(8):796-804.

38. Khalilov I, Hirsch J, Cossart R, Ben-Ari Y. Paradoxical anti-epileptic effects of a GluR5 agonist of kainate receptors. J Neurophysiol 2002;88(1):523-7.

39. Hanada T, Hashizume Y, Tokuhara N, Takenaka O, Kohmura N, Ogasawara A, et al. Perampanel: A novel, orally active, noncompetitive AMPA-receptor antagonist that reduces seizure activity in rodent models of epilepsy. Epilepsia 2011;52(7):1331-40.

40. Kramer LD, Satlin A, Krauss GL, French J, Perucca E, Ben-Menachem E, et al. Perampanel for adjunctive treatment of partialonset seizures: A pooled dose-response analysis of phase III studies. Epilepsia 2014;55(3):423-31

41. Gibbs JW $3^{\text {rd }}$, Sombati S, DeLorenzo RJ, Coulter DA. Cellular actions of topiramate: Blockade of kainate-evoked inward currents in cultured hippocampal neurons. Epilepsia 2000;41 Suppl 1:S10-6.

42. El-Azab AS, Eltahir KE. Synthesis and anticonvulsant evaluation of some new 2,3,8-trisubstituted-4(3H)-quinazoline derivatives. Bioorg Med Chem Lett 2012;22(1):327-33.

43. Dimmock JR, Sidhu KK, Thayer RS, Mack P, Duffy MJ, Reid RS, et al. Anticonvulsant activities of some arylsemicarbazones displaying potent oral activity in the maximal electroshock screen in rats accompanied by high protection indices. J Med Chem 1993;36(16):2243-52.

44. Pandeya SN, Aggarwal N, Jain JS. Evaluation of semicarbazones for anticonvulsant and sedative-hypnotic properties. Pharmazie 1999;54(4):300-2

45. Pandeya SN, Ponnilavarasan I, Pandey A, Lakhan R, Stables JP. Evaluation of p-nitrophenyl substituted semicarbazones for anticonvulsant properties. Pharmazie 1999;54(12):923-5.

46. Yogeeswari P, Sriram D, Pandeya SN, Stables JP. 4-sulphamoylphenyl semicarbazones with anticonvulsant activity. Farmaco 2004;59(8):609-13

47. Pandeya SN, Yogeeswari P, Stables JP. Synthesis and anticonvulsant activity of 4-bromophenyl substituted aryl semicarbazones. Eur J Med Chem 2000;35(10):879-86

48. Krall RL, Penry JK, White BG, Kupferberg HJ, Swinyard EA. Antiepileptic drug development: II. Anticonvulsant drug screening. Epilepsia 1978;19(4):409-28.

49. Vogel HG. Drug Discovery and Evaluation: Pharmacological Assay. New York: Berlin Springer-Verlag; 2002. p. 696-716.

50. Nishi A, Liu F, Matsuyama S, Hamada M, Higashi H, Nairn AC, et al. Metabotropic mGlu5 receptors regulate adenosine A2A receptor signaling. Proc Natl Acad Sci U S A 2003;100(3):1322-7.

51. McGeer EG, Ikeda H, Asakura T, Wada JA. Lack of abnormality in brain aromatic amines in rats and mice susceptible to audiogenic seizure. J Neurochem 1969;16(3):945-50.

52. Biswajit D, Suvakanta D, Damiki L. Design and synthesis of 4-substituted quinazoline derivatives for their anticonvulsant and CNS depressant activities. Int J Pharm Pharm Sci 2017;9(1):165-72.

53. Hemant C, Kedar L, Poorvashree J, Sneha K, Amit N, Sanjay S. In silico: Design, synthesis and pharmacological screening of some quinazolinones as possible GABA receptor agonists for anticonvulsant activity. Int J Pharm Pharm Sci 2012;4(2):466-9. 